\title{
Hubungan Program Adiwiyata Terhadap Pendidikan Agama Islam Berwawasan Karakter
}

\author{
Ikhfi Rizki Amelia ${ }^{1}$, Rofikasari Mutmainnah ${ }^{2}$ \\ ${ }^{1,2}$ Universitas Hasyim Asy'ari Jombang, Indonesia
}

\begin{tabular}{l}
\hline \hline Article Info \\
\hline Article history: \\
Received, Januari 5, 2019 \\
Accepted, Maret 3, 2019 \\
\end{tabular}

\section{Keywords:}

Program Adiwiyata Karakter Peduli Lingkungan Pendidikan Agama Islam Wawasan Karakter

\begin{abstract}
The environment is a set of parts with all the substance, effort, nature and inhabitants of the world, including human beings and their behavior that controls the life and peace of humans and other living things. The current natural problems are very alarming, lack of awareness, knowledge, understanding and ignorance so that they do not do, do not do, pretend not to know, do not like to read, even the other most dangerous cause is a greedy temperament that wants to find its own benefits. All of these cause environmental damage. With the existence of the adiwiyata program, the school population is obliged to preserve and preserve environmental knowledge through the principle of running an efficient school to uphold sustainable development. This study aims to determine the relationship of the adiwiyata program to environmental character education. The questions to be answered through this research are: 1 . The adiwiyata program at MAN 1 Jombang. 2. Character education care for the environment at MAN 1 Jombang. 3. How is the relationship between the adiwiyata program and environmental education character education. This study uses a type of field correlation research. The approach used in this research is a quantitative approach. The design of this study was expost facto. Researchers took a sample of 60 respondents from 6 classes each class taken 10 people randomly. Hypothesis testing in this study uses the Spearman correlation. Thus, the researcher tried to explain the relationship between the adiwiyata program and environmental care character education at MAN 1 Jombang. From the analysis it was found that known sig of 0,000 ( $\mathrm{sig}<0.05$ ), means that $\mathrm{HO}$ is rejected and HA is accepted. This means that there is a relationship between variable $\mathrm{X}$ (Adiwiyata Program) and Y (Environmental Care Character). Then it is also known that the coefficient value is 0.940 (positive value), which means a positive correlation (proportional), where the greater $\mathrm{X}$ then $\mathrm{Y}$ is also greater.
\end{abstract}

This is an open access article under the CC BY-SA license.

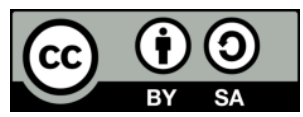

\section{Corresponding Author:}

Ikhfi Rizki Amelia

Prodi Pendidikan Agama Islam, Fakultas Agama Islam

Universitas Hasyim Asy'ari Jombang

Email: ikhfirizkiamelia6@gmail.com

\section{PENDAhUluaN}

Lingkungan hidup adalah kesatuan ruang dengan semua benda, daya, keadaan dan makhluk hidup, termasuk manusia dan perilakunya yang memengaruhi perikehidupan dan kesejahteraan manusia serta makhluk hidup lainnya. Lingkungan hidup merupakan sumber pemenuhan kebutuhan manusia untuk mendukung kehidupannya dan sebagai tempat berkembang biak semua makhluk hidup terutama manusia. Karena manusia tak akan dapat melepaskan diri dari lingkungannya. (Hariyanto,2018,51) 
Permasalahan lingkungan merupakan kondisi-kondisi dalam lingkungan yang menghalagi pemenuhan kebutuhan (Daryanto,2013,4). Berhubungan dengan larangan tersebut Allah SWT berfirman dalam Q.s Al-Qashash ayat 77. Yang artinya "Dan janganlah engkau berbuat kerusakan dibumi. Seungguhnya Allah tidak menyukai para pembuat kerusakan." Selain itu juga terdapat dalam Q.s ar-Rum ayat 41 yang artinya “ Telah tampak kerusakan bumi di darat dan laut disebabkan perbuatan tangan manusia, supaya Allah merasakan kepada mereka, sebagian dari (akibat) perbuatan mereka, agar mereka kembali (kejalan yang benar). Kedua ayat tersebut menjelaskan bahwa larangan bagi manusia untuk berbuat kerusakan dimuka bumi dan juga menjelaskan sifat-sifat Allah yang Maha Pemurah dan Penyayang, namun sengaja diberi peringatan agar mereka balik kejalur yang lurus.

Mewujudkan manusia yang memiliki kepedulian dan ramah lingkungan, maka dibutuhkan peran pendidikan khususnya disekolah, lantaran disekolah mempunyai banyak generasi muda yang menjadi pemelihara bumi, perlu digembleng kesadarannya untuk mencintai lingkungan dengan cara pembiasaan. Pembiasaan atas kepedulian terhadap lingkungan bisa berangkat dari menciptakan sekolah ramah lingkungan. Terikat atas persoalan alam yang tambah hari makin membludak dan bermacam. Maka sekolah didorong untuk mengaplikasikan pengelolaan sekolah berbasis adiwiyata. Dengan adanya pengelolaan program adiwiyata spesifiknya dilingkungan sekolah, yakni ruang dimana peserta didik melangsungkan kegiatan pembelajaran.

Tarbiyah karakter dipercaya menjadi perspektif yang sangat signifikan dalam meningkatkan nilai sumber daya manusia karena dapat memajukan suatu umat. Karakter yang berbobot perlu dibangun dan ditumbuhkan sejak dini (Gunawan, 2012,28). Artinya karakter ana k saat masih usia tersebut bisa berubahubah berdasarkan pengalaman hidupnya. Jadi membentuk karakter anak mesti dimulai sejak semula mungkin, sebab pengalaman yang dilalui anak pada perkembangan pertamanya membawa pengaruh yang besar. Tidak lepas dari peran keluarga. Karena latar belakang keluarga sebagai tolak ukur dalam kesuksesan anak dalam pendidikan.

Memanifestasikan kepedulian peserta didik terhadap lingkungan hidup, diperlukan pemahaman, pengenalan pendidikan lingkungan hidup sejak usia dini. Terbukti dalam Undang-Undang Nomor 32 Tahun 2009, pada pasal 65 ayat 2 secara jelas menyatakan bahwa setiap orang berhak mendapatkan pendidikan lingkungan hidup. Menjadi aksi berkelanjutan dalam program Kementrian Lingkungan Hidup, mempropragandakan program pendidikan lingkungan hidup dikemas dalam program adiwiyata yang pengamalannya ditata dalam peraturan Menteri Lingkungan Hidup Nomor 05 Tahun 2013 tentang panduan implementasi adiwiyata.

Berdasarkan kebijakan Menteri Negara Lingkungan hidup No 02/2009, definisi Adiwiyata adalah sekolah yang efektif dan ideal sebagai tempat mendapat seluruh bidang pendidikan dan bermacam norma dengan etika yang dapat menjadi asas manusia menuju terwujudnya kesejahteraan hidup dan cita-cita ekspansi berkerkelanjutan. Target program adiwiyata yakni melahirkan warga sekolah yang berkewajiban dalam usaha perawatan dan pengetahuan lingkungan hidup melalui tata operasi sekolah yang baik demi mengangkat perluasan berkelanjutan Adiwiyata bukan persaingan akan tetapi lebih menitik beratkan pada terbentuknya karakter yang acuh dan berbudi lingkungan secara berkepanjangan. Penerapan program adiwiyata terbentuk dari kelompok domestik, Kabupaten serta madrasah. Adapaun pelaksanaan adiwiyata dimulai dari penataan sekolah dengan mengaitkan seluruh warganya.

Area sekolah yang berdekatan dengan pertokoan dan jalan raya, mewujudkan salah satu tantangan serius yang harus dihadapi sekolah yaitu mewujudkan lingkungan sehat dan melestarikan alam sekitar. Menyadari akan adanya tantangan tersebut maka MAN 1 Jombang merasa diundang untuk memperbaiki tabiat bangsa seawal mungkin yakni melalui penataran lingkungan hidup untuk segala rakyat sekolah.

MAN 1 Jombang merupakan salah satu dari sekian banyak madrasah yang focus mengembangkan program adiwiyata. Hal tersebut dimuat dalam visi sekolah yaitu "Terbentuknya generasi yang berilmu, beramal, berakhlak mulia, unggul dalam prestasi dan kompetitif dengan berbasis lingkungan sehat" MAN 1 Jombang sudah lama menyandang tanggung jawab demi peduli terhadap lingkungan hidup. Soal ini terbukti atas dicapai seleret hasil oleh MAN 1 Jombang dalam segenap tanding yang bersangkutan dengan lingkungan. Berdasarkan uraian diatas diperoleh gambaran yang menggerakan peneliti untuk melakukan penelitian yang berjudul "hubungan Program Adiwiyata Terhadap Pendidikan Karakter Peduli Lingkungan di MAN 1 Jombang"

Berdasarkan latar belakang tersebut, agar pembahasan objek yang dikaji dalam permasalahan ini tidak melebar dan dapat lebih fokus, terarah dan terukur maka diperlukan rumusan masalah sebagai berikut: (1) Program adiwiyata di MAN 1 Jombang. (2) Pendidikan karakter peduli lingkungan di MAN 1 Jombang. (3) bagaimana hubungan program adiwiyata terhadap pendidikan karakter peduli lingkungan di MAN 1 Jombang.

Diambil dari kesimpulan pertanyaan tersebut dapat diambil maksud penelitian ini sebagai berikut: (1) untuk mengetahui dan menganalisis program adiwiyata di MAN 1 Jombang. (2) Untuk mengetahui dan menganalisis pendidikan karakter peduli lingkungan di MAN 1 Jombang. (3) Untuk mengetahui dan 
menganalisis bagaimana hubungan program adiwiyata terhadap pendidikan karakter peduli lingkungan di MAN 1 Jombang.

\section{KAJIAN PUSTAKA}

Adiwiyata merupakan salah satu program dari kementrian lingkungan hidup yang memaksa untuk menghasilkan madrasah yang beradat dan peduli terhadap lingkungan. Tujuannya yaitu menciptakan penduduk sekolah yang bertanggung jawab dan berusaha memberi perlindungan dan pengetahuan lingkungan hidup melalui mengoperasikan sekolah yang baik untuk membantu pembangunan yang berkesinambungan. (Ketut, 2018,221)

Aktivitas utama yang dimaksudkan pada struktur keorganisasiannya sekolah yang peduli dan berbudaya. memegangi pedoman dasar yaitu (1) Partisipatif bermakna seluruh warga sekolah terbelit dalam prosedur perencanaan, persiapan, pelaksanaan dan penilaian sesuai tanggung jawab dan perannya. (2) Berkelanjutan yang berarti semua kegiatan perlu dilakukan secara terprogram dan terus menerus dalam kurun waktu jangka panjang dan menyeluruh. (Endang,2018,7)

Kegiatan aksi lingkungan contohnya adalah menjaga kebersihan dilingkungan sekolah, memanfaatkan fasilitas sekolah sesuai dengan fungsinya secara tanggung jawab. Dan lain-lain.

Dalam mewujudkan program adiwiyata meliputi (a) peningkatan kebijakan sekolahh peduli lingkungan dan berbudaya lingkungan. Untuk mengkontruksikan sekolah yang acuh dan budaya lingkungan maka memerlukan beberapa prosedur sekolah yang membantu dilaksanakannya gerakan pendidikan lingkungan oleh semua warga sekolah. prosedur sekolah adalah bagian esensial dalam bentuk mengkontruksikan sekolah yang peduli dan berbudi lingkungan. (b) pengembangan kurikulum berbasis lingkungan. Dalam menyampaikan materi, gaya pembelajaran dan teknik belajar yang bervariasi dilaksanakan untuk mengalokasikan pemahaman kepada anak berhubungan dengan lingkungan hidup. (c) peningkatan aktivitas berbasis partisipatif. Kegiatan-kegiatan yang dilakukan oleh penduduk sekolah dalam pengembangan kegiatan bercirikan partisipatif diantaranya membuat kegiatan ekstrakurikuler dari aspek lingkungan (d) pengembangan dan manajemen fasilitas pendukung sekolah. Dalam mengkonstruksi program adiwiyata butuh didukung oleh sarana dan prasarana yang merepresentasikan usaha pengelolaan lingkungan (Jo Kumala, 2008,3-4)

Kemulusan aksi bersekolah dan kelas yang mendukung dapat dihasilkan juga dengan flora. Dengan tumbuh-tumbuhan sanggup menyuplai oksigen yang sanggup merealisasikan otak kita berkembang. Itulah alasannya bermakna bagi sekolah untuk mengaplikasikan program adiwiyata, di area sekolah harus ditanami tanaman dan tumbuhh-tumbuhan agar siswa menerima cadangan zat asam yang melimpah dari alam. Sehingga kegiatan belajar dapat kondusif. (Novan,2013,151-152).

Pendidikan karakter adalah anugrah pengetahuan perihal tentang jenis nilai hidup, seperti ketulusan, berbudi pekerti yang baik, afeksi dan lain-lain. (Patak, 2014, 477) sedangkan kepedulian lingkungan merupakan suatu kaidah manusia mengabadikan alam agar tidak terhambat oleh insan lain yang tidak bertanggung jawab. Karakter kepedulian seperti (1) moral persuation, contohnya mengimbau orang untuk mengabadikan lingkungan dengan memberikan pengarahan. (2) suing fordamages, misalnya menggugat kepengadilan andaikan seseorang atau tim memusnahkan lingkungan. (3) prohibition, seperti penciptaan larangan untuk merusak lingkungan. (4) pollution right and pollution charges, mempersembahkan sanksi hukuman kepada seseorang atau kelompok yang mencemari lingkungan (Patak,2014,480). Pada dasarnya manusia dijadikan khalifah oleh Allah swt untuk menjaga, mengelola dan mengolah alam semesta. Tidak hanya berakhlak kepada Allah tetapi juga berakhlak kepada ciptaannya.

\section{METODE}

Pendekatan dalam penelitian ini menggunakan kuantitatif. Penelitian kuantitatif menurut syaifuddin anwar adalah proses penelitian yang memusatkan pada angka yang diulah dengan cara statiska. Desain dalam penelitian ini termasuk dalam jenis expost facto. Exspost facto adalah penelitian dimana kumpulan variabel bebas sudah terbentuk saat peneliti mulai melakukan observasi terhadap variabel terikat. (Sukardi, 2003: 174). Adapun populasi dan sampelnya adalah siswa yang terdiri dari 6 kelas yaitu X IIK 2, X IPS 2, X IIS 1, XI MIA 4, X IIS 5, XI IIS 3. Diambil masing -masing kelas 10 anak secara acak.

Dalam penelitian ini, yang digunakan adalah sumber data primer didalamnya memuat beberapa indicator variabel yang diteliti atau data yang didapat melalui angket yang dibagikan ke responden. Selanjutnya data sekunder yang digunakan dalam penelitian ini adalah informasi yang dihasilkan dari lembaga terikat hasil penelitian yang akan diterbitkan. Data tersebut meliputi nama dan jumlah siswa MAN 1 Jombang yang menjadi responden, profil sekolah dan lain-lain. Peneliti menggunakan tekni pengumpulan data berupa teknik dokumentasi, observasi dan angket. Angket adalah cara mengumpulkan data yang 
dilakukan dengan teknik memberikan beberapa pernyataan dan pertanyaan tertulis kepada responden untuk menjawab sesuai variabel yang dibutuhkan peneliti. (Sugiyono,2016,199) peneliti menggunakan empat alternative jawaban dengan kriteria 76-100 \% baik, 60-75\% cukup, dan <60\% kurang (Suharsimi Arikunto, 1998,17)

Selanjutnya data yang sudah diperoleh, dikumpul, diolah kemudian dianalisis menggunakan analisis korelasi spearman. Untuk mengetahui bagaimana dan seberapa hubungan variabel bebas terhadap variabel terikat. Semua data yang diperoleh di analisis dengan menggunakan bantuan program SPSS Versi 16 dalam computer.

\section{HASIL DAN PEMBAHASAN}

Awalnya dari lembaga Pendidikan Guru Agama Islam yang didirikan di daerah Plandi Jombang, di tahun 1967 tepatnya tanggal 1 Januar 1968 dengan SK Negeri Nomor. 118 Tahun 1968 Madrasah tersebut dinegerikan menjadi PGAN Jombang dengan Keputusan Menteri Agama RI Nomor 19 taun 197819 Maret 1977. Pada tahun 1990, sebagai MAN Jombang dengan keputusan Menteri Agama RI Nomor 42 tahun 1992 tanggal 1 Juli 1992, dan sesuai KMA 673 tahun 2016 menjadi MAN 1 Jombang. Terletak di Jl. Dr. Wahidin Sudirohusodo No 2 Jombang. Memiliki visi terwujudnya generasi muda yang berilmu, beramal, berakhlak mulia, unggul dalam prestasi, mandiri dan kompetitif dengan berbasis lingkungan sehat. Jumlah siswa saat ini yaitu berjumlah 1418 meliputi kelas X, XI dan XII. Berjumlah siswa 473 dan siswi berjumlah 945. Memiliki sarana dan prasarana berjumlah 90 ruang. Memiliki 70 orang pendidik dengan rincian: berpendidikan terakhir S2 sebanyak 8 orang, berpendidikan S1 sebanyak 62 orang, berpendidikan D4 sebanyak 5 orang. Adapun karyawan di MAN 1 Jombang sebanyak 26 orang dengan rincian: 15 orang lulusan SMA, 5 orang berpendidikan terakhir S1, 1 orang berpendidikan S2, dan 3 orang berpendidikan terakhir D3.

Program kerja adiwiyata di MAN 1 Jombang terdiri dari tim kurikuler memuat didalamnya (1) bidang kurikuler (kurikulum, model dan media pembelajaran), (2) non kurikuler. Untuk tim aksi terdiri dari: (1) bidang pengelolaan fisik sekolah dan sekitarnya memuat didalamnya: penataan ruang kelas, penataan halaman sekolah, penataan ruang terbuka hijau, efisiensi dan penghematan energi/ sumber daya/ bahan baku. (2) bidang pembelajaran lingkungan (3) pemberdayaan warga sekolah dan sekitarnya.

Hasil observasi program adiwiyata sudah terlaksana dengan baik. sebagian usaha dan prosedur yang berhubungan dengan lingkungan hidup yang telah dilaksanakan di MA Negeri 1 Jombang diantaranya : aksi hemat SDA (listrik dan air), aksi jumat bersih, tanding kebersihan dan keindahan kelas setiap bulan, melakukan kegiatan tahunan yang bertemakan tentang lingkungan seperti peringatan hari-hari lingkungan hidup,dan lain-lain.

Untuk pelaksanaan kurikulum di MA Negeri 1 Jombang telah mencantumkan pengembangan diri terikat prosedur perlindungan dan manajemen lingkungan hidup. Pembelajaran lingkungan hidup di MA Negeri 1 Jombang digolongkan menjadi dua bagian yaitu: monolitik dan terintegrasi. Pelajaran yang monolitik untuk kelas X, XI, dan XII memasukan dalam bahan pelajaran menanam. Materi LH yang disatukan dengan mata pelajaran untuk seluruh kelas telah mendapat $80 \%$ dari jumlah seluruh mata pelajaran dan lebih dari 75\% pengajar MA Negeri 1 Jombang telah mengajarkan LH terintegrasi.

Untuk kegiatan lingkungan berbasis partisipatif seluruh warga sekolah MA Negeri 1 Jombang harus menyertai aksi lingkungan seperti jumat bersih, kegiatan menanam, program komposting, dan lain-lain. Disamping itu, seluruh pesera didik MA Negeri 1 Jombang secara sungguh-sungguh berpartisipasi dalam pokja yang terdapat di MA Negeri 1 Jombang, diataranya Pokja Taman, Toga, Kantin Sehat, Komposting, UKS, Kamar mandi dan Jumantik. Dalam mengolah sarana pendukung ramah lingkungan MA Negeri 1 Jombang membuat sebagian sumur resapan, biopori, mini komposter ditaman kelas, penyaringan sampah menjadi organik, dan anorganik. Disamping itu juga MA Negeri 1 Jombang membuat kantin sehat yang sudah tersertifikasi oleh puskesmas Pengarah dan mendapatkan pengarahan secara rutin dari pihak terkait. Seluruh makanan dan minuman dikantin MAN 1 Jombang telah terindependen dari 5P (Pemanis, Pengawet, Penyedap, Pewarna, Pengenyal). penghubung air cuci tangan sudah dipenuhi dengan sabun pembersih dan air limbahnya langsung untuk menyalurkan taman yang ada didepan kantin tersebut. Selain itu, juga disusun kebijakan pembatasan pemanfaatan sampul plastik unuk makanan dikantin dan koperasi MAN Jombang.

Dari enam puluh peserta didik yang menjadi sampel dengan 20 soal angket yang tersebar. Total skore dari angket tersebut adalah 3649. Respon siswa mayoritas menjawab Kadang-kadang sebanyak 88,23\%. Hasil observasi karakter peduli lingkungan sudah terlaksana dengan baik. Para peserta didik di MA Negeri 1 Jombang secara aktif berpartisipasi dikegiatan yang berkaitan dengan lingkungan hidup. Seperti program LH yang dilaksanakan pihak luar, Pembuatan Masterplan kawasan kota hijau Jombang yang dilangsungkan oleh pihak PU Cipta Karya Kab Jombang. Kegiatan kualitas air sungai yang dilaksanakan oleh pihak Jasa Tirta, dialog interaktif di Radio SAM FM mengenai lingkungan bekerja sama terhadap LSM Sahabat Lingkungan. Dan lain-lain. 
Rekapitulasi angket total X dan Y, yaitu variabel independen (X) memiliki jumlah 3602 dengan ratarata 60.03 dan variabel dependen (Y) memiliki jumlah 3659 dengan rata-raa 60.98. Berdasarkan kegiatan penelitian dengan desain exspost facto yang telah selesai dilakukan, maka peneliti menyimpulkan bahwa gambaran penerapan program adiwiyata bagi para responden di MAN 1 Jombang sudah cukup baik. Hal ini dibenarkan dari analisis data yang membuktikan bahwa program adiwiyata sebesar 78,54 \%. Dari hasil prosentase tersebut, dilihat pada standar penafsiran masuk dalam bilangan 76-100 \% yakni kriteria baik.

Selanjutnya gambaran karakter peduli lingkungan di MAN 1 Jombang, semua sudah dilakukan dengan baik karena mengacu pada program adiwiyata yang berujuan membentuk pribadi yang bertanggung jawab atas lingkungan sekitarnya. Hal ini bida dilihat dari analsiis data yang menunjukan bahwa karakter peduli lingkungan sebesar 88,23 \% masuk dalam kategori baik. Untuk hasil analisis statistika diperoleh hasil bahwa ada hubungan yang sangat kuat antara program adiwiyata terhadap pendidikan karakter peduli lingkungan siswa di MAN 1 Jombang dengan nilai korelasi (r) sebesar 0,940 (bernilai positif) yang berarti korelasi positif (sebanding), dimana semakin besar X maka Y juga semakin besar.

\section{KESIMPULAN}

Berdasarkan kegiatan penelitian dengan desain exspost facto yang telah selesai dilakukan, maka peneliti menyimpulkan bahwa gambaran penerapan program adiwiyata bagi para responden di MAN 1 Jombang sudah cukup baik. Hal ini dibenarkan dari analisis data yang membuktikan bahwa program adiwiyata sebesar 78,54\%. Dari hasil prosentase tersebut, dilihat pada standar penafsiran masuk dalam bilangan 76-100 \% yakni kriteria baik. Selanjutnya gambaran karakter peduli lingkungan di MAN 1 Jombang, semua sudah dilakukan dengan baik karena mengacu pada program adiwiyata yang berujuan membentuk pribadi yang bertanggung jawab atas lingkungan sekitarnya. Hal ini bida dilihat dari analsiis data yang menunjukan bahwa karakter peduli lingkungan sebesar 88,23 \% masuk dalam kategori baik. Untuk hasil analisis statistika diperoleh hasil bahwa ada hubungan yang sangat kuat antara program adiwiyata terhadap pendidikan karakter peduli lingkungan siswa di MAN 1 Jombang dengan nilai korelasi (r) sebesar 0,940 (bernilai positif) yang berarti korelasi positif (sebanding), dimana semakin besar X maka Y juga semakin besar.

\section{REFERENSI}

Praseya, Ketut dan Hariyanto, Pendidikan Lingkungan Indonesia Dasar Pedagogi dan Metodologi, Bandung, 2018.

Daryanto, Pengantar Pendidikan Lingkungan Hidup, Yogyakarta, Gava Media, 2013

Gunawan, Heri, Pendidikan Karakter Konsep dan Implementasi, Bandung, Alfabeta, 2012

Haris, Endang dan Yedi Wardiana, Sekolah Adiwiyata Panduan Implementasi Adiwiyata Mandiri di Sekolah, Jakarta, Erlangga, 2018.

Sukardi, Metodologi Penelitian Pendidikan Kompeensi dan Prakteknya, Jakarta, Bumi Aksara, 2003.

Patak, Andi Anto dan Hasbullah Said, Proceedings of the 1 st Academic Symposium on Integrating Knowledge (The 1st ASIK): Integrating Knowledge With Science and Religion, Malaysia, Ibnu Sina Institute for Fundamental Science Studies, 2014

Dewi , Jo Kumala, dkk, Buku Panduan 2008 Adiwiyata: Wujudkan Sekolah Peduli dan Berbudaya Lingkungan, Jakarta,Asdep Urusan Edukasi \& Komunikasi Lingkungan, 2008.

Wiyani, Novan Ardy, Manajemen Kelas, Jogjakarta, Ar-Ruzz Media, 2013.

Arikunto, Suharsimi Prosedur Penelitian Suatu Pendekatan Praktek, Jakarta: Rineka Cipta, 2013, Edisi Revisi. http://manjombang.sch.id/ diakses hari Senin tanggal 29/04/2019

Azwar, Syaifudin, Metode Penelitian, Yogyakarta, Pustaka Belajar, 2004 